www.periodicos.unimontes.br/index.php/caminhosdahistoria

\title{
PARCIALIDADE E AMBIGUIDADE DA JUSTIÇA NO SÉCULO XIX: A VIOLÊNCIA NO SISTEMA ESCRAVISTA NORTE-MINEIRO
}

\author{
Alysson Luiz Freitas ${ }^{1}$ \\ Yanna Beatriz Pereira Alves ${ }^{2}$
}

Resumo: O presente artigo analisa a atuação da justiça no século XIX tomando como pano de fundo a ordem escravocrata e as aspirações modernizantes do estado Imperial. Utiliza especialmente como fontes processos-crime da cidade de Montes Claros, sede da Comarca da região norte de Minas Gerais.

Palavras-chave: Justiça; Escravos; Parcialidade; Montes Claros; século XIX.

Abstract: This article analyzes the performance of justice in the 19th century taking place against a backdrop of the slavery regime and the modernizing aspirations of the Imperial state. The paper makes use of criminal proceesings from Montes Claros, the head office of the District Court in the Nothern region of Minas Gerais.

Keywords: Justice; Slaves; Parciality; Montes Claros; 19th century.

\section{Justiça e poder no Brasil Colonial}

Analisar a atuação do judiciário e dos homens envolvidos com a justiça no Brasil foi objetivo de muitos historiadores, juristas e cientistas sociais, acompanhados geralmente de impressões que se tornaram clássicas sobre os elementos que impediam o avanço da justiça e do poder público. A frase do frei Vicente do Salvador, do início do século XVII, se tornou um clássico sobre o tema, e merece espaço. O mesmo, em sua impressão sobre alguns dos principais problemas que se passavam na colônia, avaliava que no Brasil "nem um homem (....) é republico, nem zela ou trata do bem comum, senão cada um do bem particular (...) (pois) nesta terra andam as coisas trocadas, porque toda ela não é república, sendo-o cada casa." (SALVADOR, 1627. In: 1965, p. 59)

Silvia Hunold Lara, em texto sobre a temática, procura aprofundar a análise de alguns dos temas mais recorrentes sobre a justiça e o poder público no Brasil, isto é, a relação entre poder privado e poder público. Em estudo sobre a região da vila de São Salvador do Campo dos Goitocazes, na segunda metade do século XVIII, Lara demonstra alguns dos "diferentes

\footnotetext{
${ }^{1}$ Doutor em História Social pela USP. Professor do Departamento de História da Unimontes (MG). E-mail: alfluiz@yahoo.com.br. Orcid: https://orcid.org/0000-0001-5946-1408.

${ }^{2}$ Psicóloga formada pela Unifip-Moc. Pós-Graduanda em Análise Comportamental Clínica, pelo IBAC Instituto Brasiliense de Análise do Comportamento. E-mail: yanna.beatriz@hotmail.com. Orcid:
} https://orcid.org/0000-0003-1079-8274. 
usos" que a justiça, "exercida em nome do rei", podia ganhar em terras coloniais. (LARA, 2006, p. 63)

No que se refere ao período colonial, a autora demonstra que:

As análises sobre a justiça colonial têm enfatizado que os tribunais serviam menos para controlar ou coibir infrações às normas do que mediar fricções entre grupos de mesmo status social. O recurso aos tribunais seria, assim, o último passo numa longa série de conflitos, um recurso mediador quando outras possibilidades se mostravam ineficientes. Por outro lado, é comum a afirmação de que os magistrados agiam muitas vezes por constrangimento dos potentados locais, ou por interesses pessoais (embora sempre houvesse a necessidade de aparecerem como protetores dos interesses reais). Unidos às elites locais de diversos modos, aceitavam subornos para decidir certas causas, ou utilizavam sua jurisdição e seus cargos para obter vantagens econômicas. (LARA, 2006, p. 84-85)

A autora, entretanto, propõe ir além dessas impressões coloniais, demonstrando também que em muitos casos "a justiça nada decidia - ou tomava decisões ambíguas e polivalentes", e mesmo assim continuava "sendo acionada por várias partes, que a ela recorriam, sempre reiterando a necessidade de uma pronta intervenção para sanar o abuso ou dar exemplo aos demais." (LARA, 2006, p. 85)

Ao mesmo tempo, como parte de uma sociedade que era efetivamente desigual, baseada em grandes diferenças sociais e econômicas, a justiça também se apresentava como desigual, tratando de modo diverso pessoas que eram consideradas desiguais. Para Lara, os privilégios atribuídos a cada condição social ou a determinados cargos ou posições, estipulavam também tratamentos especiais. Assim, o exercício do poder judiciário implicava algo mais importante do que estabelecer ou fixar a verdade dos casos: "significava reafirmar e reforçar a rede hierárquica que ligava todos os súditos ao rei e o lugar de cada um nesse emaranhado de poderes, alçadas e jurisdições.” (LARA, 2006, p. 86)

Esses pressupostos nos permitem discutir um elemento central para a nossa proposta: compreender as relações entre público e privado no âmbito judiciário, bem como as ambiguidades e parcialidade da justiça nos casos envolvendo escravos, livres e mulheres em duas regiões do Brasil ao longo do século XIX.

\section{A justiça no Oitocentos: Brasil Império}

As análises da historiadora Silvia Lara nos permitem avaliar pelo menos dois aspectos fundamentais para a avaliação da justiça norte-mineira no século XIX. Em primeiro lugar, mesmo diante dos inúmeros problemas que envolviam o sistema judiciário no Brasil, desde a 
época colonial, o recurso à justiça era comum, legítimo, pois as pendengas encontravam muitas vezes na justiça o lócus para a solução de querelas importantes do cotidiano.

Ao longo do século XIX, no norte das Minas Gerais, veremos que a recorrência à justiça também era comum, demonstrando uma aproximação cada vez maior do poder público e da justiça frente ao cotidiano da população, mesmo que muitas vezes reforçada por relações desiguais que marcavam o sistema escravista.

Em segundo lugar, o exemplo da região de Campo dos Goitacazes, nos coloca em frente ao tratamento diferenciado que a justiça oferecia aos desiguais, e que, em última instância, reforçava e reafirmava redes de poder que se estabeleciam. Redes hierárquicas que reforçavam a desigualdade, a submissão e a dominação, elementos próprios do regime escravista brasileiro. Essa avaliação se faz imprescindível para a nossa proposta, reforçando assim a condição escrava em detrimento de determinados privilégios dos homens livres, muitas vezes comprometidos e imersos nas relações clientelares que se estabeleciam. Além disso, a relação da justiça com a violência das mulheres também apresenta contornos bem peculiares.

Não obstante, no processo de estruturação do regime imperial, novos elementos foram somados ao universo do judiciário. A justiça, à medida que avançava o século XIX, era reformulada, a partir de novos mecanismos e uma nova estrutura de poder, condizente com as mudanças políticas que o regime propunha.

Segundo Keila Grinberg, a reforma da justiça e do sistema judiciário no Brasil foi um dos temas mais recorrentes no debate político do Império.

Tida como um dos resquícios do período colonial, sobretudo pelo papel central que cabia ao imperador no exercício cotidiano, a Justiça foi objeto de discussão entre os liberais brasileiros desde o início da década de 1820 , quando muitos consideravam sua modernização elemento essencial para a própria constituição do Estado independente. (GRINBERG, In: VAINFAS, 2002, p.451)

A Constituição de 1824, nesse caminho, teria dado um importante passo na organização da justiça brasileira, junto a outros elementos criados no mesmo período. Em 1827, segundo aponta Thomas Flory, temos a criação da figura do juiz de paz, um magistrado sem formação específica, eleito pela população para exercer nas paróquias a função de juiz, especialmente em casos menores onde se poderia buscar elementos de conciliação das partes. Segundo o autor, a polêmica da criação dos juízes de paz residia no fato de ser a sua criação um dos símbolos do próprio liberalismo brasileiro da época do Primeiro Reinado, cioso do 
fortalecimento do poder local e da maior autonomia de distritos e províncias, sendo por isso combatido pelos políticos conservadores do regime monárquico. (FLORY, 1986)

Em recente tese de doutorado sobre a região do médio sertão do São Francisco, Dimas José Batista demonstra também que as mudanças no sistema judiciário vão se dar somente na segunda metade do século XIX, em meio a reformas e transformações importantes do sistema. Mesmo assim, o autor também avalia alguns dos elementos de poder e do cotidiano que se misturavam nas decisões do judiciário, impondo ao mesmo um funcionamento ambíguo e contraditório.

\begin{abstract}
Os embaraços, ambigüidades e contradições somente seriam resolvidos na segunda metade do século XIX. O Estado brasileiro legislou a respeito de todas as matérias e assuntos fossem eles econômicos, políticos, educacionais, culturais, religiosos e judiciários. Os embaraços eram frutos diretos da indistinção, da superposição e dos tênues limites e fronteiras entre as competências dos agentes da administração civil e militar. (...) As normas e leis possuíam também esse caráter difuso graças às relações sociais dominantes na sociedade brasileira que, como vimos, era em si mesma densa e difusa, ou melhor, recorria a meios extralegais para pensar a justiça e o Estado. As leis e as normas eram princípios vinculatórios que expressavam as ambigüidades e contradições da própria sociedade brasileira e mineira da época. (BATISTA, 2006, p. 57)
\end{abstract}

Um último aspecto no que diz respeito a uma das características mais marcantes do Código Criminal do Império deve ser avaliado. Segundo Grinberg, mesmo com toda a importância do código e das suas principais questões levantadas - inspirando outras nações na construção dos seus próprios códigos criminais e penais no século XIX -, eram os escravos os que mais sofriam com as penas instituídas. Dessa forma, muitos juristas e políticos do Império argumentavam que o "nível cultural" e a "evolução social" do país eram incompatíveis "com os princípios clássicos da igualdade entre seres humanos", justificando assim os direitos dos senhores em castigarem seus cativos. Além disso, o Código Criminal consolidaria, também, punições exclusivas para escravos, como "açoites e ferros, além das penas de galés e de morte.” (GRINBERG In VAINFAS, 2002, p. 146)

Veremos, não apenas para o exemplo da região norte-mineira, como para outra região, o sudeste do estado de São Paulo, que realmente os escravos "sofriam" mais com os mecanismos de poder estabelecidos, gerando assim uma distinção clara na condição cativa em relação ao universo dos livres.

Esses elementos nos levam, naturalmente, a imaginar a presença de um sistema judiciário que se encontrava em processo de reestruturação. Tal processo condicionava a justiça a reformas, no intuito de refletir mais diretamente na organização do Estado, 
adequando-se aos preceitos liberais que se manifestavam em revoluções e movimentos sociais que vinham da Europa. Todavia, no cotidiano das relações sociais, sobretudo no papel exercido pela justiça diante dos desiguais - pobres e ricos, negros e brancos, escravos e senhores, mulheres e homens - as diferenças se faziam sentir mais claramente, refletindo em uma justiça parcial e hierarquizada pelos interesses de alguns, em detrimento de outros tantos, sobretudo os cativos. As sentenças de alguns processos criminais avaliados são exemplos que ilustram essa afirmação.

\section{Homens livres e escravos: a justiça parcial no sertão das Minas}

Ao nos debruçarmos sobre os dados referentes às sentenças aplicadas aos homens livres enquanto réus dos processos referentes ao período de 1850 a $1888^{3}$ constatamos que dos 430 processos selecionados para a análise percebemos um número bem maior de processos que não determinaram penas aos réus livres. Em quase a metade da documentação $(48,4 \%)$ os réus livres foram absolvidos dos crimes praticados, somado ainda a um grande número de processos que ficaram apenas na pronúncia ou mesmo não constando sentenças $(36,3 \%)$. As prisões de homens livres pela prática, em sua maioria, de homicídios e lesões corporais, representam pouco mais de $15 \%$ de todos os processos analisados, o que claramente nos coloca diante de uma justiça com características que devem ser questionadas. Alguns exemplos devem ser explorados para que possamos estabelecer um diálogo com essa justiça oitocentista.

O forro Lino em conluio com João Teixeira de Souza Júnior e Justino José dos Santos foram indiciados como responsáveis pela morte de Roberto Xavier do Rego. A queixa foi feita pela mulher da vítima, que informou que seu marido tinha sido assassinado quando voltava de uma viagem, em tocaia armada pelos réus. O motivo do crime teria sido um anterior desentendimento entre os mesmos, ocasião em que o senhor Roberto, devido a uma briga por terras mal demarcadas, entrara com um processo contra João Teixeira e Justino, pois estes haviam espancado um compadre de Roberto. Entretanto, esse processo tinha sido

\footnotetext{
${ }^{3}$ A pesquisa em questão foi sobre a região norte de Minas Gerais, com ênfase para a cidade de Montes Claros. Para tal ver: JESUS, 2011. Para alguns autores que estudaram a região norte-mineira, a cidade de Montes Claros era a única "da região Norte de Minas que poderia merecer, ainda que com certas restrições, o nome e os direitos de cidade." (BRITO, 2006, p. 69) Em 13 de outubro de 1831, o Arraial de Formigas é transformado em vila. Já na década de 50 é elevada à categoria de cidade, com o nome atual de Montes Claros. O estabelecimento de um poder público mais efetivo contribui para a ascensão da cidade e da região ao longo do século XIX. Como salientou Tarcísio Botelho, é importante destacar ainda que este processo de ascensão de Montes Claros, na verdade, se deu através de transformações lentas e graduais, contando com uma povoação limitada e pouco dinâmica. (BOTELHO, 1994).
} 
anulado por falta de provas contundentes que levassem João Teixeira e Justino a júri. Assim, os novos autos que corriam indicavam João Teixeira e Justino como mandantes do crime executado pelo forro Lino. De acordo com as testemunhas a rixa entre as partes seria pública e notória, assim como o espancamento que teria levado ao processo anterior, anulado pela justiça. Entretanto, apesar de todas as questões levantadas contra João Teixeira e Justino, apenas Lino foi pronunciado. Ainda assim, o processo encontra-se incompleto, isto é, encerrando-se com a pronúncia do forro e a liberação dos prováveis mandantes do crime. ${ }^{4}$

Em processo do ano de 1862, a livre Ana Luisa teria sido responsável pela morte de três pessoas e pelos ferimentos em outras quatro vítimas. A autora do crime fora à casa do senhor Manoel de Sousa na tentativa de vingar-se do seu desafeto, o senhor Joaquim Cardoso de Moura. Chegando lá, atirou em todos os que estavam reunidos, não conseguindo, ironicamente, atingir o seu inimigo. Ana Luisa foi indiciada como responsável pela chacina, mas o processo não foi além da pronúncia da ré. ${ }^{5}$

No ano de 1875 a ré Angélica, conhecida como "Brava”, e seu enteado, de nome José, foram indiciados como responsáveis pelo assassinato de Antonio, marido da vítima. Segundo as testemunhas, Angélica "Brava" teria mandado José executar a vítima. No entanto, nenhuma testemunha apontou possíveis motivações para o ato. Antonio fora executado com várias facadas na virilha. A viúva, entretanto, afirmou que o marido teria morrido devido a um acidente, quando trabalhava na roça. O processo simplesmente é interrompido em meio aos depoimentos das testemunhas e, ao que tudo indica, não foi mais retomado, conforme demonstram as inúmeras folhas em branco da documentação. ${ }^{6}$

Autores que estudaram o período demonstram que o aparato judiciário era muitas vezes utilizado para resolver questões particulares, ignorando-se denúncias ou anulando-se processos "com base na lei”. Isnara Pereira Ivo reafirma a parcialidade no julgamento dos crimes locais - a região da Imperial Vila da Vitória -, demonstrando a "falta de precisão dos juízes de direito à frente da comarca (...) seja no julgamento e punição dos homens comuns, seja nos inquéritos envolvendo homens públicos. Por qualquer motivo a queixa crime podia ser considerada improcedente". (IVO, 1998, p. 90)

Não foi muito diferente, acreditamos, o que acontecia com o aparato judiciário em regiões rurais do Brasil. Os casos expostos acima envolvendo os nossos atores sociais são esclarecedores nesse sentido. A avaliação dessas sentenças nos apresenta indícios de uma

\footnotetext{
${ }^{4}$ DPDOR/AFGC, Processo Criminal no 000.080.

${ }^{5}$ DPDOR/AFGC, Processo Criminal no 000.044.

${ }^{6}$ DPDOR/AFGC, Processo Criminal no 000.204.
} 
justiça que, ao que tudo indica, misturava constantemente questões privadas com as funções públicas.

Muitos dos réus sertanejos como João Teixeira e Justino José, ou como as livres Ana Luisa e Angélica, conhecida como "Brava", acabavam impunes. A justiça, por meio dos homens da lei da região, não se mostrava capaz de colocar os réus diante do Estado e fazê-los cumprir as penas correspondentes aos crimes praticados, o que, como vimos pelos dados apresentados, aconteceu em praticamente $85 \%$ dos casos. Dos 430 processos em que os homens livres figuram como réus, em 364 ocorreram absolvições, somente pronúncia ou não consta sentença por motivos variados, como prescrição, finalizações dos processos ou pela própria fuga dos réus, muitas vezes motivados pela incapacidade do sistema judiciário em fazer valer cumprir o seu papel de agentes da justiça.

Quando avaliamos as penas aplicadas aos réus escravos, na região norte-mineira, as diferenças ficam ainda mais explícitas, nos permitindo adentrar ainda mais o universo do poder e da justiça. Dos 68 processos analisados para a apreciação da violência escrava na região ${ }^{7}$, percebemos um percentual de aproximadamente $55 \%$ dos processos com algum tipo de pena aos cativos, como prisões, castigos, reescravização ou mesmo a pena de morte natural.

Nesse sentido, mesmo que estejamos diante de uma justiça ainda na sua "infância", ao que tudo indica, com relação aos cativos, ela se fazia mais presente e eficaz. Tal situação fica ainda mais evidente quando propomos uma comparação entre a violência praticada por esses escravos junto ao universo violento dos homens livres. Notamos a existência de poucas diferenças no que se refere à violência praticada por esses agentes, independentemente das suas condições jurídicas. Assim, a proximidade e a simplicidade da vida permitiram um contato intenso e dinâmico entre os atores que compunham o universo cultural norte-mineiro, fazendo da violência um componente de aproximação dos "mundos" da escravidão. Para Ivan Vellasco:

A forte hierarquização da vida social, que possibilitava a quase todos, algum nível de distinção em relação aos socialmente inferiores, não impedia de todo as identificações horizontais entre pobres livres, forros e escravos, os quais, aliás, compartilhavam os mesmos espaços urbanos e o mesmo mundo de cultura, cujas veias corriam pelas tabernas, vendas, sambas e entrudos, nas ruas escuras e empoeiradas das vilas. (VELLASCO, 2004, p. 197)

\footnotetext{
${ }^{7}$ É importante salientar que a criminalidade escrava era menor que a criminalidade praticada por livres no sertão, como de resto para inúmeras regiões do Brasil onde a população escrava era minoria ao longo do século XIX.
} 
Entretanto, se o cotidiano permitia uma "feição desorganizada" na pretensa ordem escravista, a justiça parecia ainda se utilizar de mecanismos que reafirmavam as diferenças entre cativos e livres. Essas questões novamente nos colocam diante de uma justiça presente, mas, em vários sentidos, personalista, imprecisa e parcial.

Joaquim Nagô, mais um entre milhares e milhares de escravos espalhados pelo Brasil, sentiu na pele a condição da escravidão, reafirmada pelo papel exercido pela justiça ao longo do século XIX.

Em processo do ano de 1835, o escravo Joaquim Nagô, solteiro, com idade próxima dos 20 anos, foi acusado de assassinar o senhor Joaquim Antunes de Oliveira. Segundo a viúva, senhora Anna Francisca, o crime teria ocorrido em abril do mesmo ano, e teria sido praticado pelo referido escravo, propriedade do senhor Manoel Lopes de Oliveira. As testemunhas arroladas no processo foram concordes ao apontar o africano como o executor do crime, declarando que o mesmo teria assassinado seu opositor a facadas, tendo como motivo o fato do cativo estar agredindo uma escrava, parceira do mesmo.

Por meio do Libelo Crime Acusatório a acusação propõe-se a convencer o júri da falta grave cometida pelo cativo, apelando para questões como o "valor da vida" para o ser humano e a necessidade de "punições exemplares" na região:

P. que sendo a vida do homem o bem mais apreciável, pois que nelle se reúnem todos quantos se pode possuir, sendo a perda da mesma o maior mal que se pode imaginar (...). P. que o Reo deve ser punido com a penna (...) no gráo Maximo, para exemplo dos outros, pois que de outra forma não pode haver segurança para os Pais de famílias, e principalmente neste Centro aonde ainda se não tem feito exemplo algum. ${ }^{8}$

Joaquim Nagô não escapa da fatídica sentença, e em setembro de 1835 é condenado a sofrer a pena de morte natural. Nove meses depois, em 30 de maio de 1836, o cativo é executado, cumprindo-se a tarefa do mesmo servir "para exemplo dos outros".

Os processos analisados, nesse sentido, nos impuseram uma comparação entre a violência de escravos e livres no Brasil, por meio da atuação de uma justiça que se apresentava com posturas distintas diante das condições jurídicas dos réus. Dessa forma, um importante questionamento nos permite adentrar ainda mais o cotidiano jurídico do Brasil, isto é, os casos que envolviam as mulheres, apontando algumas das características da parcialidade na aplicação da justiça no século XIX.

\footnotetext{
${ }^{8}$ DPDOR/AFGC, Processo Criminal no 000.046, fls. 18-19v.
} 


\section{Considerações finais}

As pesquisas demonstraram que as condenações dos escravos são extremamente coerentes com as expectativas de ordem e convívio social propostas pela elite. Mesmo assim, muitas ambiguidades se vêm presentes nas relações que a justiça estabelecia com os réus, especialmente no que tange à comparação livres-escravos, homens-mulheres.

Porém, não devemos considerar essas condenações exclusivamente como o mascaramento ideológico das intenções das classes dominantes. Como alerta Edward P. Thompson:

Se a lei é manifestamente parcial e injusta, não vai mascarar nada, legitimar nada, contribuir em nada para a hegemonia de classe alguma. A condição prévia essencial para a eficácia da lei, em sua função ideológica, é a de que mostre uma independência frente a manipulações flagrantes e pareça ser justa (THOMPSON, 1987, p.354).

Thompson enfatiza a idéia do Direito como um espaço de constantes embates, cuja manifestação na sociedade visa apresentá-lo de forma potencialmente autônoma e a mudança nas suas regras faz parte do desenvolvimento das correlações de força de uma sociedade.

O autor não nega a assertiva mais geral de que o Direito exerce funções classistas, mas rejeita as teses que se iniciam com este pressuposto pois, como instrumento de mediação entre as classes, pode ter resultados imprevistos desde que os "dominados" tenham condição de recorrer ao aparato jurídico. Thompson demonstrou que ao lado do seu caráter opressivo há nas leis uma restrição ao poder desenfreado da classe dominante, reconhecendo a autonomia adquirida pela legislação a partir do momento de sua elaboração. Este ponto de vista embasou diversos trabalhos historiográficas e contribuiu para a análise do embates travados entre senhores e escravos no território brasileiro, tal como o trabalho aqui apresentado.

\section{Fontes}

DPDOR/AFGC. Divisão de Pesquisa e Documentação Regional da Unimontes/Arquivo do Fórum Gonçalves Chaves. Processos criminais. Código Criminal do Império.

\section{Referências Bibliográficas}

BATISTA, Dimas José. A administração da justiça e o controle da criminalidade no médio sertão do São Francisco, 1830-1880. Tese (Doutorado em História) - Programa de PósGraduação em História, Universidade de São Paulo, 2006. 
BOTELHO, Tarcísio Rodrigues. Famílias e Escravarias: demografia e família escrava no Norte de Minas Gerais no Século XIX. Dissertação (Mestrado em História), Programa de PósGraduação em História, Universidade de São Paulo, 1994.

BRITO, Gy Reis Gomes de. Montes Claros: da construção ao progresso - 1917-1926. Montes Claros: Unimontes, 2006.

FLORY, Thomas. El juez de paz y el jurado en el Brasil imperial. México: FCE, 1986.

GRINBERG, Keila. Verbete: In: VAINFAS, Ronaldo (org.). Dicionário do Brasil Imperial. Rio de Janeiro: Objetiva, 2002.

IVO, Isnara Pereira. A tragédia do tamanduá: um estudo de caso de poder local e de mandonismo no sertão da Bahia (1840-1895). Dissertação (Mestrado em História) - Programa de Pós-Graduação em História, Universidade Federal de Minas Gerais, 1998.

JESUS, Alysson Luiz Freitas de. No sertão das Minas: escravidão, violência e liberdade 1830-1888. São Paulo: Annablume, 2007.

JESUS, Alysson Luiz Freitas de. Cotidiano e poder nas relações sociais escravistas e pósescravidão: o sertão das Minas entre 1850 e 1915. Tese (Doutorado em História) - Programa de Pós-Graduação em História, Universidade de São Paulo, 2011.

LARA, Sílvia Hunold. MENDONÇA, Joseli Maria Nunes (orgs.). Direitos e justiças no Brasil: ensaios de História Social. Campinas, SP: Editora da UNICAMP, 2006.

SALVADOR, Frei Vicente do. História do Brasil (1627). 5. ed. São Paulo: Melhoramentos, 1965.

THOMPSON, Edward P. Senhores e caçadores: a origem da Lei Negra. Rio de Janeiro: Paz e Terra, 1987.

VELLASCO, Ivan de Andrade. As seduções da ordem: violência, criminalidade e administração da justiça - Minas Gerais - século XIX. Bauru/SP: Edusc, 2004. 